\title{
DIALÓGO CONTEMPORÂNEO: AS INIQUIDADES SOCIAIS REVERBERADAS PELA PANDEMIA DA COVID-19
}

\author{
CONTEMPORARY DIALOGUE: THE SOCIAL INIQUITIES REVERBERED BY THE COVID-19 \\ PANDEMIC
}

DOI: http://dx.doi.org/10.16891/2317-434X.v8.e3.a2020.pp800-801

Recebido em: 01.08.2020 | Aceito em: 19.09.2020

\section{Agostinho Porfirio dos Santos*a, Francisco Werbeson Alves Pereirab, Rosely Leyliane dos Santos ${ }^{c}$}

\author{
Escola Técnica de Saúdea \\ URCA-UDI ${ }^{b}$ \\ $U R C A^{C}$ \\ *E-mail: agostinhoporfirio2018@gmail.com
}

A COVID-19 é uma doença em progresso e, é responsável por inúmeras mortes em diversos países. Dados revelam que até dia 08 de setembro de 2020, globalmente, havia mais de 27 milhões de casos confirmados de COVID-19 e mais de 891 mil óbitos notificados (WHO, 2020). Esta patologia é causada por um novo coronavírus 2019 (SARS-CoV-2), inicialmente descrito como 2019-nCoV. A enfermidade pode ser originária de morcegos. Embora, a patogenicidade da doença tenha variações em virtude de fatores virais e do hospedeiro (GUO et al., 2020).

A Organização Mundial da Saúde (OMS) declarou a doença como emergência de saúde pública de interesse internacional pois o vírus apresenta alta taxa de transmissibilidade e, posteriormente, foi declarada a pandemia por COVID-19 (LAUER et al., 2020; GUO et al., 2020). Este conhecimento é importante pois há necessidade de explorar as especificidades de cada país e suas repercussões ocasionadas pela pandemia.

Mesmo diante das medidas de contingenciamento recomendadas, a mitigação do vírus é um desafio à saúde pública em virtude de que a doença acentuou as iniquidades sociais, que parecem ser históricas, quanto às disparidades regionais e mundiais para atenção à saúde dos sujeitos.

Neste contexto, reconhece-se que as iniquidades sociais fortaleceram as desigualdades e injustiças que recaem sob à saúde dos indivíduos. As iniquidades sociais são ocasionadas pelos contextos culturais, sociopolítico, econômico e biopsicossociais em que se intersecciona os determinantes sociais da saúde. As iniquidades reforçam as injustiças que dificultam a construção de uma comunidade democrática. Já as desigualdades podem se transformarem em iniquidades (FIORATI; ARCÊNCIO; SOUZA, 2016; BARRETO, 2017).
As medidas de higiene e sanitárias, que foram recomendadas para contenção da infecção viral, afloraram as desigualdades socioeconômicas existentes quanto ao saneamento básico, estrutura familiar e manutenção de renda. Além disso, a intervenção na mobilidade social dos indivíduos, que advém da necessidade de conter o ciclo de transmissão da doença, especialmente para àqueles grupos reconhecidos como vulneráveis; constitui-se desafio à vigilância em saúde. Esta resposta sanitária precisa estar alinhada às políticas públicas e sociais.

Observou-se acentuação destas fragilidades, tanto econômicas e sociais, em outras populações específicas, como a indígena e a população de rua. Outros grupos sociais e vulneráveis foram afetados de modo singular e, a depender de suas localizações geográficas, em períodos diferentes.

Recorda-se que as relações sociais entre indivíduos e suas comunidades sociais, em virtude das medidas de enfrentamento diante da pandemia, podem ter sido alteradas. $\mathrm{O}$ uso das Tecnologias Digitais de Informação e Comunicação foram amplamente disseminadas para propagação das estratégias de prevenção, informação e entretenimento. Contudo, nem todas as populações obtiveram acesso de forma igualitária e integral à internet ou dispositivos eletrônicos.

$\mathrm{O}$ acesso à internet ou limitações para seu uso, representam fragilidades a serem ultrapassadas. Estes resultados repercutiram ainda quanto à discussão acerca da continuidade do processo de ensino e aprendizagem para o alunado. A saúde física e mental de docentes e discentes e outros fatores precisam também ser incorporados nesta discussão; pois as decisões devem considerar o atual cenário sanitário regional, haja vista que o ciclo de propagação da doença parece ser distinto a depender das regiões mundiais. 
Neste contexto, outras iniquidades foram evidenciadas. A precarização das relações de trabalho tem sido amplamente discutida em virtude da fragilidade das relações trabalhistas. Com isto, reconhece-se que os esforços empreendidos para prevenção da doença e promoção da saúde perpassam aspectos assistenciais. Dentre os principais desafios a vencer a pandemia por COVID-19, destacam-se a falta de infraestrutura ou recursos limitados, práticas inadequadas de prevenção da infecção, capacidade de preparação e recursos laboratoriais inadequados (NSOUR et al., 2020). Faz-se necessário, ainda, prover quanti e qualitativamente os serviços de saúde e proteger os profissionais que atuam na atenção à saúde para com os pacientes acometidos e garantir continuidade dos cuidados (SINGHAL, 2020).

Neste sentido, as iniquidades sociais reverberadas pela pandemia em curso revelam a importância dos dados epidemiológicos, o desenvolvimento de estratégias mais abrangentes que precisam avançar e acolher às demandas das populações mais afetadas para planejar as ações de mitigação da doença e avaliação dos impactos. Reconhece-se que há necessidade de fortalecimento da gestão de saúde em níveis individual e coletivo, minimização das iniquidades sociais por meio de políticas transversais de modo a garantir a universalidade dos serviços e saúde, acessibilidade e produção do cuidado em saúde. Sugere-se fortalecimento dos estudos científicos, da ciência, que ampliem este tema.

\section{REFERÊNCIAS}

BARRETO, M.L. Desigualdades em Saúde: uma perspectiva global. Ciênc. saúde colet., v.22, n.7, p. 2097 2108, 2017. DOI: 10.1590/1413-81232017227.02742017

FIORATI, R.C.; ARCÊNCIO, R.A.; SOUZA, L.B. de. As iniquidades sociais e o acesso à saúde: desafios para a sociedade, desafios para a enfermagem. Rev. Latino-Am. Enfermagem,v.24, e2683, 2016.

GUO, Y-R. et al. The origin, transmission and clinical therapies on coronavirus disease 2019 (COVID-19) outbreak - an update on the status. Mil Med Res. v. 7, n. 1. 2020.

LAUER, S. A. et al. The Incubation Period of Coronavirus Disease 2019 (COVID-19) From Publicly Reported Confirmed Cases: Estimation and Application. Ann Intern Med., v.172, n.9, p.577-582, 2020. DOI:10.7326/M2005042020.

NSOUR, M. Al et al. The Role of the Global Health Development/Eastern Mediterranean Public Health Network and the Eastern Mediterranean Field Epidemiology Training Programs in Preparedness for COVID-19. JMIR Public Health Surveill. v. 6, n. 1, e18503, 2020. DOI: 10.2196/18503.

SINGHAL, T. A Review of Coronavirus Disease-2019 (COVID-19). Indian J Pediatr. v. 87, n. 4, p. 281-286, 2020. DOI: 10.1007 / s12098-020-03263-6

WORLD HEALTH ORGANIZATION. WHO Coronavirus Disease (COVID-19) Dashboard. Disponível em: 〈https://covid19. who.int >. Acesso em: 08 set. 2020. 